2. Papiris S, Kotanidou A, Malagari $K$, et al. Clinical review: severe asthma Crit Care 2002;6:30-44.

3. Bryan CL, Jenkinson SG. Oxygen toxicity. Clin Chest Med 1988;9:141-52.

4. Thomson AJ, Webb DJ, Maxwell SR, et al. Oxygen therapy in acute medical care. BMJ 2002;324:1406-7.

5. O'Driscoll BR, Howard LS, Davison AG; British Thoracic Society. BTS guideline for emergency oxygen use in adult patients. Thorax 2008;63(Suppl VI):1-68.

\section{Authors' response: hyperoxia in acute asthma}

We appreciate the comments by Snelson and Tunnicliffe ${ }^{1}$ regarding our study of the effects of high concentration oxygen therapy in acute exacerbations of asthma. ${ }^{2}$ We concur with the view that the effect of high concentration oxygen therapy on arterial carbon dioxide pressure $\left(\mathrm{PaCO}_{2}\right)$ is not clinically relevant in all patients presenting to the emergency department (ED) with acute severe asthma. However, we consider that the 3.9-fold greater risk of patients developing an increase in transcutaneous partial pressure of carbon dioxide $\left(\mathrm{PtCO}_{2}\right) \geq 8 \mathrm{~mm} \mathrm{Hg}(22 \%$ vs $6 \%$ in the high concentration vs titrated oxygen groups, respectively) is likely to be of clinical relevance in life-threatening asthma. Even in our study, which excluded patients who were unable to speak or perform spirometry due to breathlessness, all 10 patients who had a final $\mathrm{PtCO}_{2} \geq 45 \mathrm{~mm} \mathrm{Hg}$ had received high concentration oxygen therapy. These findings suggest that the routine administration of high concentration oxygen therapy in the ED setting is a determinant of respiratory failure, a recognised marker of near fatal asthma. This probably also applies to the routine use of high concentration oxygen therapy during ambulance transfer in patients with severe asthma, as has been noted in chronic obstructive pulmonary disease, ${ }^{3}$ but this was not assessed in our study.

While permissive hypercapnia is an approach to the management of mechanical ventilation for severe asthma, this relates to intubated patients, in whom the purpose is to reduce the risk of complications associated with hyperinflation. ${ }^{4}$ It certainly does not apply to prehospital or ED care.

We agree that there are many potential risks associated with hyperoxia, including but not limited to reductions in coronary and cerebral blood flow, decreased cardiac output, increased oxidative stress, delay in recognising a clinical deterioration and rebound hypoxaemia if oxygen therapy is abruptly stopped. However, in respiratory disorders such as severe asthma where there is significant ventilation/perfusion (V/Q) mismatch, hypercapnia represents another potential risk of high concentration oxygen therapy that needs to be recognised in clinical practice.

\section{Kyle Perrin, Meme Wijesinghe, Mark Weatherall, Richard Beasley}

Medical Research Institute of New Zealand, Capital and Coast District Health Board, Wellington, New Zealand and Department of Medicine, University of Otago Wellington, Wellington, New Zealand

Correspondence to Dr Kyle Perrin, Medical Research Institute of New Zealand and Capital and Coast District Health Board, Level 7, CSB building, Wellington Hospital, Riddiford Street, Wellington 6021, New Zealand; kyle.perrin@mrinz.ac.nz

\section{Competing interests None.}

Provenance and peer review Commissioned; internally peer reviewed.

Accepted 5 December 2011

Published Online First 6 March 2012

Thorax 2012;67:834.

doi:10.1136/thoraxjnl-2011-201469

\section{REFERENCES}

1. Snelson C, Tunnicliffe B. Correspondence: Hyperoxia in acute asthma. Thorax 2012;67:833-4.

2. Perrin K, Wijesinghe $M$, Healy $B$, et al. Randomised controlled trial of high concentration versus titrated oxygen therapy in severe exacerbations of asthma. Thorax 2011:66:937-41.

3. Austin MA, Wills KE, Blizzard L, et al. Effect of high flow oxygen on mortality in chronic obstructive pulmonary disease patients in prehospital setting: randomised controlled trial. BMJ 2010:

\section{1:c5462.}

4. Corbridge TC, Hall JB. The assessment and management of adults with status asthmaticus. Am J Respir Crit Care Med 1995;151:1296-316.

\section{Increasing smokers' risk perception improves CT screening participation}

We read with interest the article by Patel et $a l^{1}$ and wish to comment on their findings with specific regard to smokers' risk perception, motivation and low participation rates in CT screening programmes.

Based on the studies to date, there is a consistent theme that smokers' participation in CT screening programmes for lung cancer is poor when their motivation is low and much greater when their perception of risk of lung cancer is high. ${ }^{12}$ Despite overwhelming public health messaging, smokers continue to smoke, in large part, because they perceive their own risk from smoking to be low. This self-perception of low risk (termed optimistic bias) maintains a low level of motivational tension (the fear that smoking might indeed be harmful). ${ }^{3}$ We propose that optimistic bias can be undermined, and motivational tension increased, when smokers are confronted with adverse 'personalised' risk data. ${ }^{3}$ With advances in the understanding of the clinical and genetic factors underlying lung cancer susceptibility, we have developed a lung cancer susceptibility risk model. ${ }^{4}$ This model assigns current and former smokers to moderate, high and very high risk. In a group of randomly selected current smokers, $84 \%$ took up the offer of risk testing and, surprisingly, quit rates 6 months after testing were $20 \%, 36 \%$ and $40 \%$, respectively ( $28 \%$ overall)..$^{5}$ Just as with triggering a decision to quit smoking, we suggest uptake of (and possibly adherence to) CT screening might be improved by risk testing that enhances risk perception, undermines optimistic bias and increases motivational tension. ${ }^{3}$

We tested this proposition in a scenariobased telephone questionnaire involving 350 current and former smokers (mean age 67, age range $44-86$ years, $59 \%$ male and mean pack years 45). When told of a survival benefit with CT screening versus no screening, we found $68 \%$ agreed to undertake CT screening while $95 \%$ agreed to gene-based risk testing. Likelihood of participation in CT screening for lung cancer was 25\% higher (absolute increase) in those testing high and very high risk compared with those at moderate (average) risk. Collectively, the results of these studies support our suggestion that optimistic bias can be undermined, and motivational tension increased, in current and former smokers through the use of personalised risk testing. We suggest that personalised risk testing, incorporating genetic markers of susceptibility, may help identify and motivate 'high risk' smokers to engage in CT screening.

\section{R P Young, R J Hopkins}

Schools of Biological Sciences and Health Sciences, University of Auckland, Auckland, New Zealand

Correspondence to Dr Robert $P$ Young, Respiratory Genetics Group, University of Auckland, P0 Box 26161, Epsom 1344, Auckland, New Zealand; roberty@adhb.govt.nz

Funding RPY, and the funding of his research, has been supported by grants from the University of Auckland, Health Research Council of New Zealand and Synergenz BioSciences Ltd. Synergenz BioSciences Ltd holds patents for gene-based risk testing for lung cancer susceptibility.

\section{Competing interests None.}

Contributors RPY: researched and wrote the correspondence. RJH: researched, wrote and edited the correspondence.

Provenance and peer review Not commissioned; externally peer reviewed.

Accepted 22 December 2011

Published Online First 16 January 2012

Thorax 2012;67:834-835.

doi:10.1136/thoraxinl-2011-201453

\section{REFERENCES}

1. Patel D, Akporobaro A, Chinyanganya N, et al Attitudes to participation in a lung cancer screening trial: a qualitative study. Thorax 2012;67:418-25.

2. Montes U, Seijo LM, Campo A, et al. Factors determining early adherence to a lung cancer screening protocol. Eur Respir J 2007;30:532-7. 
3. Young RP, Hopkins RJ, Smith M, et al. Smoking cessation: the potential role of risk assessment tools as motivational triggers. Postgrad Med $\mathrm{J}$ 2010;86:26-33.

4. Young RP, Hopkins RJ, Whittington CF, et al. Individual and cumulative effects of GWAS susceptibility loci in lung cancer: associations after sub-phenotyping for COPD. PLoS One 2011;6:e16467.

5. Hopkins RJ, Young RP, Hay B, et al. Gene-based lung cancer risk score triggers smoking cessation in randomly recruited smokers. Am J Respir Crit Med 2011;183:A5441.

\section{Need to test impact of DNA-based risk scores}

Young and Hopkins highlight the emerging data suggesting that smokers who perceive themselves at a lower risk of lung cancer may be less likely to take part in, and less likely to adhere to, lung cancer screening programmes. ${ }^{1-4}$ Their work suggesting that a risk score that includes genetic markers of susceptibility of lung cancer alters optimistic bias, improves quit rates in smokers and may encourage participation in lung cancer CT screening is exciting.

Risk scores that include genetic risk data may reach the parts that other risk scores fail to reach. In the lung-SEARCH screening trial, we found that a negative family history specifically led some smokers to decline participation in screening. Being told that risk of lung cancer is 'in your genes' may specifically counter perceptions of protection from a negative family history. This proposal could be tested with further qualitative exploration of risk perception in smokers offered participation in screening trials However, in a Cochrane review of the literature, Marteau et $a l^{5}$ found no overall impact of presenting DNA-based risk scores, although studies are few and of variable quality.

Lung cancer screening programmes especially need to target those at the highest risk in order to maximise cost effectiveness. DNA-based risk profiling may contribute to better targeting for those enrolling in lung cancer screening programmes. This too needs to be tested prospectively.

Chris Griffiths, ${ }^{1}$ Deesha Patel, ${ }^{1}$ Ajiri Akporobaro, ${ }^{1}$ Nyasha Chinyanganya, ${ }^{2}$ Allan Hackshaw, ${ }^{3}$ Clive Seale, ${ }^{1}$ Robert Walton, ${ }^{1}$ Stephen Spiro ${ }^{4}$

${ }^{1}$ Centre for Primary Care and Public Health, Blizard Institute, Queen Mary, University of London, London, UK; ${ }^{2}$ Department of Thoracic Medicine, University College London Hospital NHS Foundation Trust, London, UK; ${ }^{3}$ Cancer Research UK and University College London Cancer Trials Centre, London, UK; ${ }^{4}$ Royal Brompton Hospital, London, UK
Correspondence to Chris Griffiths, Centre for Primary Care and Public Health, Blizard Institute, Queen Mary, University of London, London, UK; c.j.griffiths@qmul.ac.uk

\section{Competing interests None.}

Provenance and peer review Commissioned; internally peer reviewed.

Accepted 7 January 2012

Published Online First 28 February 2012

Thorax 2012;67:835.

doi:10.1136/thoraxjnl-2012-201596

\section{REFERENCES}

1. Patel D, Akporobaro A, Chinyanganya N, et al Attitudes to participation in a lung cancer screening trial: a qualitative study. Thorax 2012;67:418-25

2. van den Bergh KA, Essink-Bot ML, van Klaveren RJ, et al. Informed participation in a randomised controlled trial of computed tomography screening for lung cancer. Eur Respir $J$ 2009:34:711-20.

3. Montes U, Seijo LM, Campo A, et al. Factors determining early adherence to a lung cancer screening protocol. Eur Respir J 2007;30:532-7.

4. Silvestri GA, Nietert PJ, Zoller J, et al. Attitudes towards screening for lung cancer among smokers and their non-smoking counterparts. Thorax 2007:62:126-30.

5. Marteau TM, French DP, Griffin SJ, et al. Effects of communicating DNA-based disease risk estimates on risk-reducing behaviours. Cochrane Database Syst Rev 2010;(10):CD007275. 